-ORIGINAL ARTICLE-

Volume 13 Issue 42021

DOI: 10.21315/eimj2021.13.4.2

ARTICLE INFO

Received: 30-05-2021

Accepted: 12-07-2021

Online: 30-12-2021

\section{Exploring the Viability of Online Problem-Based Learning Through the Lens of Students and Teachers}

\author{
Amna Riaz', Rehan Ahmed Khan², Mahwish Arooj', \\ Muhammad Zafar lqbal ${ }^{3}$ \\ ${ }^{1}$ Department of Medical Education, University College of Medicine and \\ Dentistry, The University of Lahore, PAKISTAN \\ ${ }^{2}$ Riphah Academy of Research and Education, Riphah International \\ University, Rawalpindi, PAKISTAN \\ ${ }^{3}$ Department of Medical Education, College of Medicine, Imam \\ Abdulrahman Bin Faisal University, Dammam, SAUDI ARABIA
}

To cite this article: Riaz A, Khan RA, Arooj M, Iqbal MZ. Exploring the viability of online problem-based learning through the lens of students and teachers. Education in Medicine Journal. 2021;13(4):19-31. https://doi.org/10.21315/eimj2021.13.4.2

To link to this article: https://doi.org/10.21315/eimj2021.13.4.2

\title{
ABSTRACT
}

This study aimed at exploring the perceptions of students and teachers regarding the viability of the online problem-based learning (PBL) approach. The study also aimed to report the perceived merits and demerits of online PBL and offer suggestions to improve it further. To achieve these objectives, a qualitative exploratory study was conducted at the College of Medicine, The University of Lahore from July 2020 to November 2020. Employing purposive sampling, 12 students and 11 teachers were recruited, with experience in both online and face-to-face PBL. The perceived merits and demerits of online PBL were inquired in focus group discussions. Moreover, suggestions to improve the online PBL environment were elicited from both stakeholders. The data was recorded, and then inductively coded and thematically analysed using Atlis.ti software. Students displayed active participation, improved learning and self-regulation during online PBL. The participants valued online PBL as a resourceful, convenient and flexible learning strategy. Some demerits of online PBL were also reported, including student passivity, low motivation and poor concentration, which were mainly attributed to the lack of physical presence. Suggestions to improve the online PBL environment included virtual use of simulation patients and infographics, faculty development, student orientation and technical support. We conclude that online PBL can be used as an effective strategic alternative to face-to-face modality. However, certain challenges exist in online PBL that can jeopardise students' learning processes. Efforts need to be made to fully capture the essence of the online PBL environment.

Keywords: Online PBL, Online problem-based learning, Face-to-face PBL, Traditional PBL, Distance learning

CORRESPONDING AUTHOR Amna Riaz, Department of Medical Education, University College of Medicine and Dentistry, The University of Lahore, 1-km Defence Road, Lahore, Pakistan

Email: dramnazafar@outlook.com 


\section{INTRODUCTION}

Problem-based learning (PBL) is a constructivist, student centred pedagogy, where students work in small groups to address authentic contextualised problem scenarios (1). PBL shifts the focus of learning from memorisation to the application of knowledge and skills by working through realistic clinical scenarios (2). It allows students to establish a link between theory and practice, improves their clinical reasoning, critical thinking and problem solving skills (3-4). While solving the presented problem, the students identify learning gaps and needs, that assume responsibility to regulate their learning (5).

Due to its evidence-based utilities, many medical schools across the globe have adopted PBL as a core instructional strategy in their training curricula (6-7). A recent development has been the introduction of synchronous online PBL in health professions education (8-10). In synchronous online PBL, all educational activities are conducted virtually, without physical contact, via commercially available applications such as Zoom, Microsoft Team etc. (11).

To date, few studies have sought to compare face-to-face and online PBL, advocating that online PBL has the potential to enhance accessibility, authenticity, communication and self-directed and collaborative learning (12-13). In another study, Kim et al. reported that computer-based scaffolding effectively improves higher-order cognitive skills among PBL students (14). However, critics of online education claim it is often challenging for teachers to effectively engage students, keep them motivated and enrich their learning (15-16). The novel online PBL approach might also pose challenges for the students, as they are expected to learn new functionality and translate this effectively to a new pedagogical setting (17-18). For instance, a case study of synchronous online PBL also resulted in mixed findings. On one hand, the students perceived online PBL as a flexible and accessible alternative to face-to-face PBL and stated that it worked relatively well for them. On the other hand, some students faced difficulties with internet connectivity and the limited depth of discussions. The facilitators also encountered challenges during online PBL, noting that it requires additional effort and preparation relative to campus-based sessions (11).

The mixed findings in the literature suggest that the viability of online PBL needs to be established through the lens of students and teachers. Gaining a better understanding of student and teacher perspectives regarding the online PBL environment is imperative to tailor this instructional strategy as per educational needs. Therefore, this study aimed to explore the perceptions of students and teachers to report the perceived merits and demerits of online PBL and offer suggestions to improve it further.

\section{MATERIALS AND METHODS}

Based on the principles of phenomenography, an exploratory study was planned to elicit details regarding the subjective and in-depth experiences of students and teachers. Phenomenography is a research approach that refers to the exploration of how different people conceive or understand their experiences of a particular phenomenon in different ways (19). It differs from phenomenology in that phenomenographic studies focus on exploring the variations in diversified experiences, whereas phenomenological studies aim at clarifying the meaning, structure or understanding of a specific phenomenon (19). Since this study aimed at exploring the experiences of two different stakeholders (students and teachers) participating in online PBL, phenomenographic approach was found to be more suitable methodology.

The study was conducted at the College of Medicine, The University of Lahore from July 2020 to November 2020. In the 
medical college, an integrated, modulebased curriculum is in place and PBL is one of the core instructional strategies in pre-clinical years. In response to the recent COVID-19 crisis, the medical college shifted to online PBL to efficiently minimise the impact of the pandemic on students' learning and to ensure continuous delivery of education during the lockdown. The total number of PBLs varied by module, but at least one PBL was conducted per week. The online PBL followed the same three phases as a face-to-face modality: (a) problem analysis and identification of learning objectives, (b) individual selfdirected learning, and (c) collaborative group discussions. The teachers remotely facilitated the sessions with their assigned group of students via a Zoom application. During the sessions, the students were given the roles of chair, scribe and members, and the scribe used a virtual whiteboard to take notes. Additionally, to support students' learning, the facilitators also shared their educational resources with their groups.

A homogenous purposive sampling technique was used to recruit the participants for this study. Only those students and teachers with knowledge and experience of PBL were recruited on a voluntary basis. The participants (students and teachers) were selected from the $1 \mathrm{st}$ and 2nd (pre-clinical) years of the MBBS programme, and all had prior experience of both face-to-face and online PBL. It was mandated that the participants must have attended at least $10 \mathrm{PBL}$ sessions. In total, 12 students and 11 teachers participated in the focus group discussions. Of the 11 participating teachers, 10 were female and one was male. Of the 12 students, eight were females and four were male.

A separate inventory was designed for students and teachers for the focus group discussion (see Appendix). Prior to the data collection, the interview inventory was piloted on two students and two teachers to check the clarity, understanding and relevance of the questions. The feedback received following pilot testing was used to further refine the questions. These participants were not included in the main study.

After finalising the inventory, an email invite, along with a consent form was sent to all the participants recruited. A convenient time was finalised for a separate focus group discussion session with both students and teachers. Both focus group interviews were conducted via the Zoom application. Before formally starting each interview, the interviewer (AR) attained consent from the participants to video record the session. The session was also audio-recorded on a separate device to fully capture the data. During each interview, a pre-designed and validated inventory was used to collect responses; meanwhile, follow-up questions were also used on needs basis. On average, the duration of each focus group discussion was almost one hour.

Both the focus group interviews were transcribed verbatim using Microsoft Word, version 2019. Non-verbal communications, such as laughter or hesitation were also included in the transcripts. After data transcription, the transcripts were shared with participants for member checking, followed by data coding. A line-by-line, inductive coding technique was used to extensively analyse the data and to generate themes and sub-themes. Codes with common concepts were clustered together and labelled as primary categories. Based on the subjective interpretation of two authors (AR and MZI), the primary categories were then clustered into main categories, which were eventually formed into themes. To maintain a level of objectivity, the emergent themes were reviewed individually by the other two authors (MA and RAK). The final report moved beyond a mere description of the codes and themes, as we used direct quotations from the participants to construct and defend the narrative in the study findings.

Permission to conduct this research project was sought from the Ethical Review Board (ERB) of The University 
of Lahore (ERC/08/20/12). Additionally, a formal consent was taken from all study participants to anonymously report their viewpoints.

\section{RESULTS}

The data analysis revealed 148 codes and 41 sub-themes, which were grouped into 10 themes based on their association to the study objectives. In the results section, we have divided the themes into three sections for a better understanding of the findings. In the first and second section, the perceived merits and demerits of the online PBL environment have been elaborated. The third section describes the suggestions of students and teachers for improving online PBL. Table 1 provides an overview of the emerging themes along with representative quotations from the participants.

\section{Merits of Online PBL}

Various merits were iterated by students and teachers, which have been classified under four themes: active student participation, improved learning experiences, learning environment flexibility and resource friendliness.

\section{Active student participation}

Both student and teacher interviewees expressed that most students in their groups actively participated in the online sessions and had productive discussions on the presented problem. Interestingly, many female student interviewees shared that they felt more comfortable in online sessions, and they preferred online PBL over face-to-face. This comfort level gave them confidence to speak and participate actively. Active female participation was also found in the opinions of teachers.

Table 1: Perceived merits, demerits and suggestions for improvement of online PBL

\begin{tabular}{|c|c|c|}
\hline Categories & Themes & Representative quotations \\
\hline \multirow{3}{*}{$\begin{array}{l}\text { Merits of online } \\
\text { PBL }\end{array}$} & $\begin{array}{l}\text { Active student } \\
\text { participation }\end{array}$ & $\begin{array}{l}\text { It is difficult for me to speak face-to-face. Maybe because I have less } \\
\text { confidence level. And my speaking skills are not that good. Maybe } \\
\text { that's why I felt more confident online. (S10) } \\
\text { The girls took the roles of scribes and leaders in online PBL. Before, } \\
\text { they used to say, "no we don't want to take these roles". That was } \\
\text { one difference that I felt in online PBL. (TO2) }\end{array}$ \\
\hline & $\begin{array}{l}\text { Improved } \\
\text { learning } \\
\text { experience }\end{array}$ & $\begin{array}{l}\text { Lockdown happened all of a sudden. I was worried how we are } \\
\text { going to cover the syllabus. So, I often motivate myself that "no, } \\
\text { you have to pay attention and study because no one will help you } \\
\text { except yourself". (SO5) } \\
\text { Some of our scribes and leaders shared the LOs even before time } \\
\text { and asked me if there was the need to add something to these } \\
\text { LOs. They asked if they skipped something, or... if they were doing } \\
\text { enough. It showed that they were taking interest. (T02) }\end{array}$ \\
\hline & $\begin{array}{l}\text { Flexible } \\
\text { learning } \\
\text { environment }\end{array}$ & $\begin{array}{l}\text { Because I have long hours of traveling, so going and coming back } \\
\text { home is a tough routine for me. In online } \mathrm{PBL} \text {, we have more time } \\
\text { to search content and study as compared to face-to-face. I use } \\
\text { different websites of educational resource and extract the material } \\
\text { related to the problem. I enjoy online PBL more. (S02) }\end{array}$ \\
\hline
\end{tabular}

(continued on next page) 
Table 1: (continued)

\begin{tabular}{|c|c|c|}
\hline Categories & Themes & Representative quotations \\
\hline & $\begin{array}{l}\text { Resource } \\
\text { friendliness }\end{array}$ & $\begin{array}{l}\text { It (online PBL) is economical. Generally, the institute needs to } \\
\text { arrange } 7-8 \text { rooms... and the same number of facilitators obviously. } \\
\text { Then printed material is also required. So, a lot of resources can be } \\
\text { saved in online PBL. In colleges where sufficient financial resources } \\
\text { are not available, they can benefit a lot from online PBLs. (T11) }\end{array}$ \\
\hline & & $\begin{array}{l}\text { Our online sessions were recorded during the Zoom meetings. So, I } \\
\text { use the recordings of specific lectures of anatomy, physiology, and } \\
\text { biochemistry related to the PBL topic. It got easy for me to make } \\
\text { PBL preparation and study more as compared to face-to-face. (S01) }\end{array}$ \\
\hline \multirow{3}{*}{$\begin{array}{l}\text { Demerits of } \\
\text { online PBL }\end{array}$} & $\begin{array}{l}\text { Passive } \\
\text { student } \\
\text { contribution }\end{array}$ & $\begin{array}{l}\text { I think face-to-face PBL is better because I find it more interesting. } \\
\text { Doing it face-to-face, sitting in one room, discussing problem with } \\
\text { my fellow mates is a better learning experience. There, discussions } \\
\text { were more meaningful. (S06) }\end{array}$ \\
\hline & $\begin{array}{l}\text { Technical and } \\
\text { technological } \\
\text { issues }\end{array}$ & $\begin{array}{l}\text { I live in a remote area where signals are not very strong. So, I often } \\
\text { get internet problem. If connectivity issue happens in online, then } \\
\text { suddenly the whole rhythm breaks down and I lose focus. (S02) } \\
\text { There were some students whose connection used to lag. Their } \\
\text { answers used to come a little late. So, we had to wait for what they } \\
\text { were saying. It was time consuming and frustrating. (T07) } \\
\text { When we do PBL in the class, we have a white board and scribe uses } \\
\text { it. Then everybody is interested while watching it. But when we } \\
\text { were doing it online, there were technical problems. Some students } \\
\text { didn't know how to use a virtual whiteboard. Other students } \\
\text { couldn't understand what scribe is writing. (TO4) }\end{array}$ \\
\hline & $\begin{array}{l}\text { Negative } \\
\text { impact on } \\
\text { learning }\end{array}$ & $\begin{array}{l}\text { Teamwork is less in online PBL because we don't find the time to } \\
\text { interact with each other. In campus, we have self-study periods, we } \\
\text { don't have class then. We sit in the café and discuss the PBL and } \\
\text { divide roles. That's not possible in online PBL. (S12) } \\
\text { There are back-to-back lectures, sometimes without break. I feel } \\
\text { exhausted. At that time, my mind does not have much capacity to } \\
\text { process new information. The cognitive load increases and I find } \\
\text { difficult to concentrate then. (S10) }\end{array}$ \\
\hline \multirow{3}{*}{$\begin{array}{l}\text { Suggestions for } \\
\text { improvement }\end{array}$} & $\begin{array}{l}\text { Technical } \\
\text { support }\end{array}$ & $\begin{array}{l}\text { Some students are not well versed with educational applications. If } \\
\text { we could train them on basic educational applications, then many } \\
\text { issues could be solved. (T03) }\end{array}$ \\
\hline & $\begin{array}{l}\text { Captivating } \\
\text { educational } \\
\text { resources }\end{array}$ & $\begin{array}{l}\text { You can bring a patient in online session related to the disease of } \\
\text { the PBL. Then we can ask him questions related to his problem. It } \\
\text { will be just like a hospital visit. That will be very interesting. ( } \mathrm{SO4} \text { ) } \\
\text { I think video-based PBL scenario will engage more students in } \\
\text { online sessions. We can do this through video of a stimulated } \\
\text { patient. He tells his scenario and then students discuss it. Then the } \\
\text { next trigger is given. So that students become curious. (T11) }\end{array}$ \\
\hline & $\begin{array}{l}\text { Teachers } \\
\text { and students } \\
\text { training }\end{array}$ & $\begin{array}{l}\text { Lockdown was so sudden that we didn't find any time to train } \\
\text { ourselves or the students. I think there should be dedicated training } \\
\text { on online PBLs because it's very different than face-to-face. (TO8) }\end{array}$ \\
\hline
\end{tabular}




\section{Improved learning experience}

Student interviewees expressed that since education delivery was completely online during the lockdown, they felt more responsible to regulate their learning. Teachers also felt that students showed more responsible behaviour during online PBL. Additionally, some students also observed an improvement in their learning during sessions because of the online consultation of educational resources in real time, which is difficult during face-to-face sessions.

\section{Flexible learning environment}

The most highlighted advantage of online PBL over face-to-face modality was convenience and flexibility. Many students expressed that attending PBL online offered a less hectic routine and less wastage of time. They shared that since they did not face any commute issues, they had more time in hand to focus on their studies. The extra time also gave them enough opportunities to do more research on the given problem as compared to face-to-face PBL.

\section{Resource friendliness}

A couple of teachers mentioned that online PBL approach is resource friendly as much less logistics are required to facilitate an online session as compared to campus based PBL. Another advantage of online PBL shared by students was the utility of session recordings as a useful learning source.

\section{Demerits of Online PBL}

Although many advantages were highlighted by the students and teachers, some issues were also reported that could jeopardise the PBL process.

\section{Passive student contribution}

Some student interviewees expressed that either they did not contribute actively, or their group members showed less contribution in online PBLs as compared to face-to-face modality. When asked, lack of time, interest, and/or motivation were found to be the main reasons behind less active contribution. Another highlighted factor for less active student participation was related to the lack of physical interaction. Many students initially found online PBL less interesting than face-to-face because of the lack of physical presence. With time, some of the students got adjusted to the online environment while others could not.

\section{Technical and technological issues}

Almost all students and teachers at some point expressed that the two major issues they encountered during online PBL were poor internet connectivity and lack of technology awareness. Poor internet speed and other connectivity problems not only interfered with students' learning but also caused demotivation, frustration and lack of concentration. Students expressed that they felt lagging behind the group in case they got disconnected in the middle of the session. Teachers also expressed that they felt frustrated when students get disconnected in the middle of discussions. In addition, some students struggled with online tools and technologies, which was also reported by some teachers. Another issue highlighted by many teachers was switching off the camera by students which caused less interactive and productive group activity.

\section{Negative impact on learning}

Some additional issues, mentioned by students only, were that they observed less teamwork in online PBL as compared to face-to-face, which negatively influenced their learning. Students expressed that they struggled to carry out collaborative learning due to the lack of physical presence. Some students also experienced lack of concentration and increased cognitive load in online PBL as compared to face-to-face. These issues were mainly because of the continuous online classes and a sense of loneliness. 


\section{Suggestions to Improving Online PBL}

While exploring ways to improving online PBL environment, the three emergent suggestions were: technical support, captivating educational resources, and teachers and students training.

\section{Technical support}

Almost all interviewees, students and teachers alike, expressed that technical support is essential to ensure successful conduction of an online PBL. In the domain of technical support, the first and foremost recommendation was to ensure a reliable and highspeed internet connection to avoid any connectivity issues. The second suggestion was to train students on how to use technology. This suggestion was given by teachers only.

\section{Captivating educational resources}

Many students and teachers suggested using captivating material in the presented scenario to grab students' attention, to keep them engaged and to generate interest and curiosity among students. Students suggested that incorporating videos of simulated patients would serve as an effective approach to trigger students' curiosity and to engage them in discussion simultaneously. Additionally, students further suggested to incorporate interesting videos, graphics and pictures of real patients in the given PBL scenario so that their interest can be generated.

\section{Teachers and students training}

Teachers expressed that they had to shift to online PBL suddenly because of the COVID-19 lockdown. Therefore, there was not enough time to train the faculty in the context of online PBL. They suggested that a dedicated faculty development programme focused on online teaching would be helpful. Some teachers also felt the need to introduce student orientation sessions. They suggested that the students should be trained on the importance of PBL, its process and their role in it.

\section{DISCUSSION}

In this study, we explored the perceptions of those stakeholders directly involved in online PBL - students and teachers. The findings of the study suggest online PBL is useful for improving student participation, enthusiasm and self-regulation, which is congruent with previous studies. For instance, Chicharro et al. reported that online learning helps develop self-regulation amongst the students, and that they seem to enjoy it (20). Studies also suggest that students, when learning through distance education platforms, tend to have more effective learning strategies and a higher level of motivation (21).

Another interesting finding in our study was the proactive participation by female students. This finding could be attributed to cultural norms, whereby females are usually shy and often tend to speak less in face-to-face conversations. A disadvantage of their shyness is that these students are easily dominated by talkative individuals, which can jeopardize their learning process as well as their personal development (22). Although evidence suggests that interpersonal and communication skills are best developed in face-to-face learning settings, tele practice has been recommended as an effective approach to developing communication skills among shy and quiet students (23). Moreover, mentoring can also play a vital role in helping female students overcome any mental barriers, insecurities and fears they experience (24).

This study shows that students' level of enthusiasm could vary depending upon the platform. Since the students' and teachers' interactions differ in both online and face-to-face learning, students experience different motivators in each environment (25). Similarly, the lack of 
physical appearance in the online learning environment can also be perceived as an inhibitor of rapport building and in-depth discussion $(11,15)$. Another possible factor associated with a lack of active contribution at this time could be the isolation caused by the lockdown, which has negatively impacted students' wellbeing and learning motivation (26-28).

Our results suggest that online PBL is a more convenient approach than campusbased education because students do not have to go through transportation and daily preparation problems. Additionally, online PBL also offers an opportunity to participate from different geographical locations, which was vital during lockdown when students from different cities and towns were housebound. These findings are consistent with previous studies, wherein students typically prefer distance education for reasons of convenience and reduced costs (29). The issue of cost-effectiveness when associated with online PBL is not only applicable to students but to the institutes as well. In online PBL, institutes require far less logistics and resources, which can be advantageous in resource-poor institutes and/or countries.

This study's findings also demonstrate that online PBL can be helpful in improving students' learning via digital resources. The students explored varied online education resources and used technological aids more frequently during online PBL. The increased use of digital resources could be attributed to the augmented use of technology education for the health professions (30). Digital education learning resources go beyond textbooks, offering material that is not only informative but also engaging. Digitalisation of online PBL can potentially lead to better contextual learning and a deeper understanding of complex information as compared to traditional PBL (31-32).

While certain advantages of online PBL have been reported, it is not without limitations, and there is room for improvement. The most critical challenge with online PBL is being able to engage students in discussions and keep them motivated so that they can secure maximum benefits from group discussions. The lack of physical appearance in online PBL makes it challenging for teachers and students to visualise and interpret facial expressions and gestures, which can jeopardise group dynamics and individual students' concentration. However, certain efforts can be made to engage students, generate their curiosity and keep them motivated. For instance, incorporating simulated patients virtually or their videos in a PBL scenario could serve as an effective strategy $(9,34)$. Using virtual patient simulations in online learning is a documented educational technique used to help students focus on core information that is relevant to authentic clinical scenarios (34-36). Therefore, teachers could use videos simulations or actual virtual patients when presenting problem scenarios so that students can relate directly to the patient.

Another concern is that facilitating tutorials online requires additional effort and preparation when compared to that for face-to-face sessions $(11,37)$. Thus, it is important to prepare teachers for this new educational environment, which could be expedited through a structured faculty development programme. Unfortunately, teachers sometimes have inflated perceptions of their teaching skillset, which can subconsciously result in incompetence (38-39). In light of this argument, a detailed SWOT analysis by administrative bodies could help outline the areas to be targeted in teacher training. On the other hand, the struggle of medical students to actively participate in the discussion and effectively handle technology during virtual learning could seriously threaten the viability of online PBL. To address this issue, students should be oriented on the value and process of PBL to attain maximum learning benefits. Moreover, training sessions should be introduced to help students learn how to use different technological tools available in the virtual education context. 
This study is not without limitations. First, it is a single institute-based study, and therefore its findings are difficult to generalise. Further studies should explore the views of students and teachers from other institutes where online PBL is in place, so that more holistic conclusions can be drawn. The second limitation is the small purposive sample size. Although in-depth focus group discussions were conducted to comprehensively explore the perceptions of the participants, other teachers and students might have different perceptions regarding the effectiveness of online PBL. Finally, the participants might have responded in what they perceived to be a socially desirable manner, which might have not provided realistic insights that we were aiming for.

\section{CONCLUSION}

This study concludes that online PBL can be useful for improving student participation, providing meaningful learning experiences and helping students selfregulate their learning. Online PBL also offers a more flexible, easily accessible and cost-effective learning environment relative to the face-to-face approach. A disadvantage of online PBL is that it might cause some students to participate less actively than desired, as they find face-to-face learning more engaging and productive. Nonetheless, the virtual use of simulated patients could serve as an effective strategy to engage students, generate curiosity and keep them motivated. Finally, it is recommended that both students and teachers be adequately trained for the online educational environment. While acknowledging the potential demerits of online PBL, we conclude that online PBL can serve as a viable alternative to the conventional modality.

\section{ETHICAL APPROVAL}

Permission to conduct this research project was sought from the Ethical Review Board (ERB) of The University of Lahore (ERC/08/20/12). 


\section{APPENDIX}

\section{Interview Guide}

\begin{tabular}{|c|c|}
\hline Interview questions from students & Interview questions from teachers \\
\hline $\begin{array}{l}\text { How was your online PBLs experience during } \\
\text { COVID-19? }\end{array}$ & $\begin{array}{l}\text { How was your online problem-based facilitating } \\
\text { experience during COVID-19? }\end{array}$ \\
\hline How did you adapt to the new learning format? & How did you adapt to the new teaching format? \\
\hline What benefits did you experience of online PBLs? & What benefits did you experience of online PBLs? \\
\hline Did you experience any issues during online PBLs? & Did you experience any issues during online PBLs? \\
\hline $\begin{array}{l}\text { If Yes, then; what issues did you face in online PBLs } \\
\text { that may have affected your learning? }\end{array}$ & $\begin{array}{l}\text { If Yes, then; what issues did you face in online PBLs } \\
\text { that may have affected students' learning? }\end{array}$ \\
\hline $\begin{array}{l}\text { What similarities do you see between online and } \\
\text { face-to-face sessions? }\end{array}$ & $\begin{array}{l}\text { What similarities do you see between online and } \\
\text { face-to-face sessions? }\end{array}$ \\
\hline $\begin{array}{l}\text { What differences do you see between online and } \\
\text { face-to-face sessions? }\end{array}$ & $\begin{array}{l}\text { What differences do you see between online and } \\
\text { face-to-face sessions? }\end{array}$ \\
\hline $\begin{array}{l}\text { Which modality provides more self-directed } \\
\text { learning opportunities? Online or face-to-face } \\
\text { PBLs? Why }\end{array}$ & $\begin{array}{l}\text { Which modality provides more self-directed } \\
\text { learning opportunities? Online or face-to-face } \\
\text { PBLs? Why? }\end{array}$ \\
\hline $\begin{array}{l}\text { In which modality you were more motivated to } \\
\text { contribute? Online or face-to-face? Why? }\end{array}$ & $\begin{array}{l}\text { In which modality students were more motivated } \\
\text { to contribute? Online or face-to-face? Why? }\end{array}$ \\
\hline $\begin{array}{l}\text { What solutions can you suggest for improving } \\
\text { online PBL? }\end{array}$ & $\begin{array}{l}\text { What solutions can you suggest for improving } \\
\text { online PBL? }\end{array}$ \\
\hline $\begin{array}{l}\text { Do you want to add anything? Please go ahead if } \\
\text { you do. }\end{array}$ & $\begin{array}{l}\text { Do you want to add anything? Please go ahead if } \\
\text { you do. }\end{array}$ \\
\hline
\end{tabular}




\section{REFERENCES}

1. Bate E, Hommes J, Duvivier R, Taylor DCM. Problem-based learning (PBL): getting the most out of your students - their roles and responsibilities: AMEE guide no. 84. Med Teach. 2014;36(1):1-12. https:// doi.org/10.3109/0142159X.2014.848269

2. Usmani A, Sultan ST, Ali S, Fatima N, Babar S. Comparison of students and facilitators' perception of implementing problem based learning. J Pak Med Assoc. 2011;61(4):332-5.

3. Goss B, Reid K, Dodds A, McColl G. Comparison of medical students' diagnostic reasoning skills in a traditional and a problem based learning curriculum. Int J Med Educ. 2011;2:87-93. https://oi. org/10.5116/ijme.4e64.055a

4. Khan IA, Al-Swailmi FK. Perceptions of faculty and students regarding problem based learning: a mixed methods study. J Pak Med Assoc. 2015;65(12):1334-8.

5. Yew EHJ, Goh K. Problem-based learning: an overview of its process and impact on learning. Heal Prof Educ. 2016;2(2):75-9. https://doi.org/10.1016/j.hpe.2016.01.004

6. Servant-Miklos VFC, Woods NN, Dolmans DHJM. Celebrating 50 years of problem-based learning: progress, pitfalls and possibilities. Adv Heal Sci Educ. 2019;24(5):849-51. https://doi.org/10.1007/ s10459-019-09947-9

7. Hung W, Dolmans DHJM, van Merriënboer JJG. A review to identify key perspectives in PBL meta-analyses and reviews: trends, gaps and future research directions. Adv Heal Sci Educ. 2019;24(5):943-57. https://doi. org/10.1007/s10459-019-09945-x
8. Munyengabe S, Yiyi Z, Haiyan H, Hitimana S. Primary teachers' perceptions on ICT integration for enhancing teaching and learning through the implementation of one laptop per child program in primary schools of Rwanda. Eurasia J Math Sci Technol Educ. 2017;13(11):7193-204. https://doi. org/10.12973/ejmste/79044

9. Kononowicz AA, Woodham LA, Edelbring S, Stathakarou N, Davies D, Saxena N, et al. Virtual patient simulations in health professions education: systematic review and meta-analysis by the digital health education collaboration. J Med Internet Res. 2019;21(7):e14676. https://doi. org/10.2196/14676

10. Hussin WNTW, Harun J, Shukor NA. Problem based learning to enhance students critical thinking skill via online tools. Asian Soc Sci. 2018;15(1):14. https://doi. org/10.5539/ass.v15n1p14

11. Erickson S, Neilson C, O’Halloran R, Bruce C, McLaughlin E. 'I was quite surprised it worked so well': student and facilitator perspectives of synchronous online problem based learning. Innov Educ Teach Int. 2020:1-12. https://doi.org/10.1080/1470329 7.2020 .1752281

12. Verstegen DML, de Jong N, van Berlo J, Camp A, Könings $\mathrm{KD}$, van Merriënboer JJG, et al. How e-learning can support PBL groups: a literature review. In: Educational technologies in medical and health sciences education. Switzerland: Springer Nature; 2016. p. 9-33.

13. Zarea Gavgani V, Hazrati H, Ghojazadeh M. The efficacy of digital case scenario versus paper case scenario on clinical reasoning in problem based learning: a systematic review and meta-analysis. Res Dev Med Educ. 2015;4(1):17-22. https://doi.org/https://doi. org/10.15171/rdme.2015.003 
14. Kim NJ, Belland BR, Walker AE. Effectiveness of computer-based scaffolding in the context of problem-based learning for STEM education: Bayesian meta-analysis. Switzerland: Springer Nature; 2018.

15. Tsai CW, Chiang YC. Research trends in problem-based learning (PBL) research in e-learning and online education environments: a review of publications in SSCI-indexed journals from 2004 to 2012. Br J Educ Technol. 2013;44(6):185-90. https://doi.org/10.1111/bjet.12038

16. Coiado OC, Yodh J, Galvez R, Ahmad K. How COVID-19 transformed problembased learning at Carle Illinois College of Medicine. Med Sci Educ. 2020;30(4): 1353-4. https://doi.org/10.1007/s40670020-01063-3

17. Tawfik AA, Kolodner JL. Systematizing scaffolding for problem-based learning: a view from case-based reasoning. Interdiscip J Probl Learn. 2016;10(1):6. https://doi. org/10.7771/1541-5015.1608

18. Tawfik AA, Kim K, Hogan M, Msilu F. How success versus failure cases support knowledge construction in collaborative problem-solving. J Educ Comput Res. 2019;57(6):1376-99. https://doi. org/10.1177/0735633118799750

19. Larsson J, Holmström I. Phenomenographic or phenomenological analysis: does it matter? Examples from a study on anaesthesiologists' work. Int J Qual Stud Health Well-being. 2007;2(1):55-64. https:// doi.org/10.1080/17482620601068105

20. Chicharro FI, Giménez E, Sarria Í. The enhancement of academic performance in online environments. Mathematics. 2019;7(12):1219. https://doi.org/10.3390/ math7121219
21. Wang $\mathrm{CH}$, Shannon DM, Ross ME. Students' characteristics, self-regulated learning, technology self-efficacy, and course outcomes in online learning. Distance Educ. 2013;34(3):302-23. https://doi.org/10.1080/ 01587919.2013 .835779

22. De Leng BA, Dolmans DHJM, Van De Wiel MWJ, Muijtjens AMM, Van Der Vleuten CPM. How video cases should be used as authentic stimuli in problem-based medical education. Med Educ. 2007;41(2): 181-8. https://doi.org/10.1111/j.13652929.2006.02671.x

23. Downing K. Personality and online learning. In: Cases on interactive technology environments and transnational collaboration: concerns and perspectives. Pennsylvania, United States: IGI Global; 2010. p. 126-39.

24. Williams-Nickelson C. Mentoring women graduate students: a model for professional psychology. Prof Psychol Res Pract. 2009;40(3):284. https://doi.org/10.1037/ a0012450

25. Alkiş N, Temizel TT. The impact of motivation and personality on academic performance in online and blended learning environments. Educ Technol Soc. 2018;21(3):35-47.

26. Meo SA, Abukhalaf DAA, Alomar AA, Sattar K, Klonoff DC. COVID-19 pandemic: impact of quarantine on medical students' mental wellbeing and learning behaviors. Pakistan J Med Sci. 2020;36(COVID19-S4). https://doi. org/10.12669/pjms.36.COVID19-S4.2809

27. Rose S. Medical student education in the time of COVID-19. JAMA. 2020;323(21):2131-2. https:/doi. org/10.1001/jama.2020.5227 
28. Naqvi HA. Mental health in the aftermath of COVID-19: a new normal. J Pak Med Assoc. 2020;70(5):S141-4. https://doi. org/10.5455/JPMA.30

29. Bower M, Kenney J, Dalgarno B, Lee MJW, Kennedy GE. Patterns and principles for blended synchronous learning: engaging remote and face-to-face learners in richmedia real-time collaborative activities. Australas J Educ Technol. 2014;30(3):26172. https://doi.org/10.14742/ajet.1697

30. Jin J, Bridges SM. Educational technologies in problem-based learning in health sciences education: a systematic review. J Med Internet Res. 2014;16(12):e251. https://doi. org/10.2196/jmir.3240

31. Car LT, Myint Kyaw B, Dunleavy G, Smart NA, Semwal M, Rotgans JI, et al. Digital problem-based learning in health professions: systematic review and meta-analysis by the digital health education collaboration. J Med Internet Res. 2019;21(2):1-12. https://doi. org/10.2196/12945

32. Gavgani VZ, Hazrati H, Ghojazadeh $M$. The efficacy of digital case scenario versus paper case scenario on clinical reasoning in problem based learning: a systematic review and meta-analysis. Res Dev Med Educ. 2015;4(1):17-22. https://doi.org/10.15171/ rdme. 2015.003

33. Zhou J, Zhou S, Huang C, Xu R, Zhang Z, Zeng $S$, et al. Effectiveness of problem-based learning in Chinese pharmacy education: a meta-analysis. BMC Med Educ. 2016;16(1):23. https://doi.org/10.1186/ s12909-016-0546-Z
34. Lee J, Kim H, Kim KH, Jung D, Jowsey $\mathrm{T}$, Webster CS. Effective virtual patient simulators for medical communication training: a systematic review. Med Educ. 2020;54(9):786-95. https://doi.org/10.1111/ medu. 14152

35. Motola I, Devine LA, Chung HS, Sullivan JE, Issenberg SB. Simulation in healthcare education: a best evidence practical guide. AMEE guide no. 82. Med Teach. 2013;35(10):e1511-30. https://doi.org/10.31 09/0142159X.2013.818632

36. Al-Dahir S, Bryant K, Kennedy KB, Robinson DS. Online virtual-patient cases versus traditional problem-based learning in advanced pharmacy practice experiences. Am J Pharm Educ. 2014;78(4):76. https:// doi.org/10.5688/ajpe78476

37. de Jong N, Verstegen DML, Könings KD. The role of the e-tutor in synchronous online problem-based learning: a study in a master public health programme. Br J Educ Technol. 2018;49(3):385-97. https://doi. org/10.1111/bjet. 12554

38. Iqbal MZ, AlSheikh MH. Factors affecting the transfer of training to the workplace after a faculty development programme: what do trainers think? J Taibah Univ Med Sci. 2018;13(6):552-6. https://doi.org/10.1016/j. jtumed.2018.11.001

39. Iqbal $\mathrm{MZ}$, Könings $\mathrm{KD}$, Al-Eraky $\mathrm{M}$, AlSheikh $\mathrm{MH}$, van Merrienboer JJG. Development of an entrustable professional activities (EPAs) framework for small group facilitators through a participatory design approach. Med Educ Online. 2020;25(1):1694309. https://doi.org/10.108 0/10872981.2019.1694309 